\title{
THE ROLE OF Diet, PHYSICAL ACTIVITY, BODY FATNESS, AND BREASTFEEDING IN BREAST CANCER IN YOUNG WOMEN: EPIDEMIOLOGICAL EVIDENCE
}

\author{
I. Isabelle Romieu ${ }^{1,2 *}$, A. Amadou ${ }^{3}$ AND V. Chajes ${ }^{4}$
}

${ }^{1}$ Center of Research on Population Health, National Institute of Public Health, Cuernavaca, Mor., Mexico; ${ }^{2}$ Hubert Department of Global Health, Emory University, Atlanta, Georgia, USA; ${ }^{3}$ Molecular Pathology of Cancers and Biomarkers Group, Institute for Advanced Biosciences, University Grenoble Alpes, France; ${ }^{4}$ International Agency for Research on Cancer, Lyon, France

\begin{abstract}
The incidence of breast cancer $(B C)$ is rising worldwide, with an increase in aggressive neoplasias in young women. Traditionally, $B C$ in young women has been thought to be etiologically driven, primarily by genetic/hereditary factors. However, these factors explain only a small proportion of BCs, pointing to a role of the environment. Suspected factors responsible for this increase include lifestyle changes, notably alcohol consumption, diet with high intake of refined carbohydrates and saturated fat and low intake of polyunsaturated fatty acids (PUFA), fiber and vitamins (such as folate, vitamin D, and carotenoids), low physical activity, and body fatness, all of which may act from childhood and adolescent years through adulthood. Despite limited data on BC in young women, evidence points to the importance of a healthy lifestyle, including high intake of vegetables, fruits, legumes, fish, and poultry, low intake of sugar and fat, daily physical activity, low alcohol consumption, steady weight, and breastfeeding in preventing BC in young women. Preventive efforts should begin in early life to provide important benefits much later in life by shifting the long-term trajectory of risk accumulation. Data from Latin America and developing regions are still sparse. There is a need to harmonize studies in a global effort to fight the rise of $\mathrm{BC}$ incidence in low- and middle-income countries, where the nutritional transition is occurring rapidly. The stratification of BC by specific tumor characteristics needs to be considered since risk factors may be more particularly associated with the promotion of, or protection from, a defined type of BC.
\end{abstract}

Key words: Breast cancer. Breastfeeding. Diet. Physical activity. Obesity. Young women.

\section{INTRODUCTION}

\section{Occurrence and definition}

Breast cancer $(B C)$ is the second most common cancer worldwide, and by far the most frequent cancer among women, with an estimated 1.67 million new cancer cases diagnosed in 2012 ( $25 \%$ of all cancers) ${ }^{1}$. Of these cancers, it is estimated that one-third occurs before age 50. This proportion varies according to geographic areas

Corresponding author:

*Isabelle Romieu

Instituto Nacional de Salud Pública

Av. Universidad, 655

Col. Santa María Ahuacatitlán

C.P. 62100, Cuernavaca, Mor, México

E-mail: iromieu@gmail.com and socioeconomic status. In less developed countries, more than $20 \%$ of BC cases occur in women aged < 45 years, while in developed countries, the corresponding figure is only $12 \%$. For example, in Latin America, the proportion of incident cases among women $<45$ years is close to $20 \%$, with some variation between countries, from $7 \%$ in Uruguay to $23 \%$ in Bolivia; while in North America and the European Union, this proportion is close to $7 \%$, contrasting with sub-Saharan Africa and Asia (India), where the proportion approximates $23 \%{ }^{2}$.

Received for publication: 21-04-2017

Approved for publication: 25-05-2017

doi: $10.24875 / R I C .17002263$ 
$B C$ is a heterogeneous disease. The presence or absence of estrogen and/or progesterone receptor (ER, PR) expression and the molecular pathological characteristics are essential to predict tumor clinical behavior and response to treatment modalities ${ }^{3}$. Five major $B C$ subtypes have been identified: luminal $A$, luminal $B$, normal-cell like, human epidermal growth factor receptor-2 (HER2) overexpressing, and basalcell-like, which are routinely identified using a set of five immunohistochemistry biomarkers: ER, PR, HER2, epidermal growth factor receptor, and cytokeratins $5 / 6^{3}$. BC in young women has aggressive biological characteristics, in particular, a high proportion of triple-negative (TN) and HER2-positive cancers, and an elevated risk of local recurrence and contralateral $\mathrm{BC}^{4}$. In addition, $\mathrm{BC}$ among young women tends to be diagnosed at advanced stages, resulting in poorer outcomes than BC in older premenopausal and postmenopausal women ${ }^{5}$, and with higher mortality rates compared to older women ${ }^{4,6}$.

Traditionally, BC in young women has been thought to be primarily etiologically driven by genetic/hereditary factors ${ }^{4}$. However, although it is more likely associated with increased familial risk, only a relatively small proportion of cases (10\%) is attributable to inherited germline variations in the known familial $B C$ risk genes $(B R C A 1 / B R C A 2)^{7}$, particularly in those women with a very strong family history of breast or ovarian cancer ${ }^{7}$. Other genomic factors, including mutations in tumor suppressor and oncogenes, copy number variation, and epigenetics, are likely implicated in cancer initiation and progression among young women. However, these alterations do not fully explain the carcinogenesis and subsequent progression among young women ${ }^{8}$.

Given the magnitude of the problem of $B C$ in young women and the growing epidemic in less developed countries, it is of major importance to evaluate the role of modifiable risk factors. Because of the inconsistency in the definition of "young women" in breast oncology, where most articles refer to women under 35,40 , and 45 years or premenopausal as "young," our definition of "young" will be inclusive using updated information on risk factors among women $<45$ years old or premenopausal women.

\section{MATERIALS AND METHODS}

To review the epidemiologic literature regarding the association of diet, physical activity, body fatness, and breastfeeding with $\mathrm{BC}$ in young women, we conducted a MEDLINE and PubMed search, including all publications, using diet, dietary intake, fatty acids, carbohydrate, glycemic index (Gl), glycemic load (GL), B-vitamins, folate, vitamin D, carotenoids, soy, fiber, alcohol consumption, dietary patterns, physical activity, body fatness, height, weight, body mass index (BMI), waist circumference (WC), hip circumference, waist-to-hip ratio (WHR), healthy lifestyle index, breastfeeding, early life, adolescence, premenopausal $B C, B C$ in young women, case-control and cohort studies, Latin America and Mexico as keywords. We then examined the references from the identified articles, previous review and meta-analyses focusing specifically on BC in young women or premenopausal BC. Our review includes most recent references on the association between diet, physical activity, body fatness, and breastfeeding and BC in young/premenopausal women, with an additional focus on early life factors.

\section{RESULTS}

Several subtypes of BC have been identified as potentially related to specific risk factors. However, only recently have studies focused on BC subtypes, in part because of sample size limitation for tumors with lower frequency.

The large body of literature on nutrition and BC has been reviewed by an international panel gathered by the World Cancer Research Fund (WCRF), and this has been updated in $2010^{\circ}$. Among risk factors related to $\mathrm{BC}$ in premenopausal women, only alcohol consumption has been strongly linked (strong evidence/probable) to an increase in BC. Body fatness, lactation and vigorous physical activity have also been strongly linked (strong evidence/probable) to a protective effect. The evidence that adult attained height is linked to $\mathrm{BC}$ has been rated as convincing (strong evidence/convincing) while greater birth weight to a probable (strong evidence/ probable) increased risk (Table 1). However, most of the studies reviewed were conducted in high-income countries, and data were in several cases insufficient to analyze the different subtypes of BC. In the following part of this paper, we review the recent literature associated to $\mathrm{BC}$ risk related to diet, physical activity, body fatness, and breastfeeding; we present results of studies conducted in Latin America; we emphasize the role of early life exposure. 
Table 1. Risk factors of Breast Cancer in young women

\begin{tabular}{|c|c|c|}
\hline \multirow[t]{2}{*}{ Evidence } & \multicolumn{2}{|c|}{ Food, nutrition, physical activity and breast cancer (Premenopause) } \\
\hline & Decreases risk & Increases risk \\
\hline \multicolumn{3}{|l|}{ Strong evidence } \\
\hline Convincing & & Adult attained height* \\
\hline Probable & $\begin{array}{l}\text { Vigorous physical activity } \\
\text { Body fatness } \\
\text { Lactation }\end{array}$ & Alcoholic drinks greater birth weight \\
\hline \multicolumn{3}{|l|}{ Limited evidence } \\
\hline Limited - suggestive & $\begin{array}{l}\text { Non-starchy vegetables } \\
\text { Dairy products } \\
\text { Food containing carotenoid } \\
\text { Diet high in calcium } \\
\text { Physical activity** }\end{array}$ & \\
\hline Limited - no conclusion & $\begin{array}{l}\text { Dietary fibre; non-starchy } v \\
\text { products; meat (red and pro } \\
\text { fat; fatty acid composition; } \\
\text { D; vitamin C; vitamin E; calc } \\
\text { weight gain; sedentary beh }\end{array}$ & $\begin{array}{l}\text { (ER+ BC) and fruits; pulses (legumes) soya and soya } \\
\text { ish; poultry; eggs; fat and oils; total fat; vegetable } \\
\text { caemic index; folate; vitamin B6, vitamin B12, vitamin } \\
\text { ements; iron; phytoestrogens; dietary patterns; adult } \\
\text { rgy intake }\end{array}$ \\
\hline $\begin{array}{l}\text { Substantial effect on risk } \\
\text { unlikely }\end{array}$ & & \\
\hline
\end{tabular}

*Adult attained height is unlikely directly to modify the risk of cancer. It is a marker for genetic, environmental, hormonal, and also nutritional factors affecting growth during the period from preconception to completion of linear growth. ${ }^{\dagger}$ Evidence for an effect in ER- breast cancer only. "Evidence stronger in ER- breast cancer. **Physical activity of all types: occupational, household, transport and recreational Adapted from the World Cancer Research Fund/American Institute for Cancer Research9.

\section{Early life exposure}

Early life, childhood, and adolescence appear to be important periods for exposure to $\mathrm{BC}$ risk because the breast has not yet completed cell differentiation. The US Institute of Medicine calls for priority research to include childhood and the critical window from menarche to first pregnancy to better guide future primary prevention strategies ${ }^{10}$. Higher peak height growth velocity and early age at menarche each increase the risk of premenopausal $\mathrm{BC}^{11}$.

Behavioral factors such as adolescent physical activity, alcohol consumption, and dietary intake are also important. Women who are active during childhood, adolescence, and young adulthood may have a lower risk of premenopausal $\mathrm{BC}^{9,12,13}$. The average reduction in $\mathrm{BC}$ risk associated with physical activity at different ages has been estimated to be $16 \%$ for adolescence, $8 \%$ for early adulthood, $15 \%$ for middle adulthood, and $17 \%$ for women aged 50 years ${ }^{14}$.

Adolescent alcohol consumption has been directly related to the risk of premalignant and invasive $B C$ in prospective cohort studies. In the Nurses' Health Study II (NHS II), alcohol consumption between menarche and first full-time pregnancy (FFTP), adjusting for alcohol consumption after first pregnancy, was associated with an $11 \%$ increased risk for BC and a
$16 \%$ increase for benign breast diseases per $10 \mathrm{~g}$ of alcohol/day (one drink) ${ }^{15}$. In addition, a stronger effect was observed with a binge drinking pattern ${ }^{16}$. In the European Prospective Investigation into Cancer and Nutrition (EPIC), alcohol intake was associated with both pre- and post-menopausal cancer. However, BC risk was stronger among women who started drinking before FFTP. An increase of $10 \mathrm{~g}$ of alcohol/day was related to an $8 \%$ (95\% confidence interval $[\mathrm{Cl}]$ : 2-14) increased the risk of $\mathrm{ER}^{-}$tumors in women who start drinking before FFTP, while no association could be detected among women who start drinking after FFTP17.

The evidence on the contribution to $\mathrm{BC}$ risk of childhood and adolescent dietary exposure is less documented. Soy intake, particularly in childhood, has been related to a lower risk of $\mathrm{BC}^{18}$. Data from the NHS $\|^{19}$ suggest that meat intake and fatty diet during adolescence are related with an increase of premenopausal $\mathrm{BC}^{20,21}$. A significant linear association was observed with every additional $100 \mathrm{~g}$ of red meat consumed per day during high school (20\% increase in risk; $95 \%$ $\mathrm{Cl}$ : 0-43). In addition, fat intake in the highest quintile (142 g/day) was associated with a 35\% increase in risk when compared to fat intake in the lowest quintile (105 g/day) (95\% Cl: 0-81). Fiber intake during adolescence was also related to the risk of $\mathrm{BC}$; women 
in the highest quintiles ( $24 \mathrm{~g} /$ day) had $23 \%$ less risk of $\mathrm{BC}$ than women in the first quintile $(12.2 \mathrm{~g} /$ day $)$ ( $95 \% \mathrm{Cl}:-44$ to -10$)$. Regarding dietary patterns, a marginal inverse association was observed between a "prudent" dietary pattern, characterized by high intake of vegetables, fruits, legumes, fish and poultry, and premenopausal BC. Women in the fifth quintile had a $16 \%$ lower risk of premenopausal BC compared with the first quintile ( $95 \% \mathrm{Cl}:-23$ to 4 ). Scoring higher on the Alternative Healthy Eating Index, a measure of diet quality that assesses conformance to dietary guidelines for Americans, including information on unsaturated fat ${ }^{22}$, was inversely associated with premenopausal BC and this association appeared to be stronger for $\mathrm{ER}^{-} / \mathrm{PR}^{-}$tumors. An overall healthy diet during adolescence, similar to the prudent dietary pattern, or adherence to the Alternative Healthy Eating Index may contribute to reduce the risk of $\mathrm{BC}^{23}$. In addition to reducing the risk of early cancers, prevention efforts that begin in early life may also provide important benefits much later in life by shifting the long-term trajectory of risk accumulation ${ }^{24}$.

\section{Body fatness}

Higher adiposity in childhood and adolescence has been inversely associated with premenopausal BC, in both hormone receptor-positive and hormone receptor-negative. In addition, larger recalled body size in childhood and adolescence is inversely associated with subsequent BC risk, independently of current body $\operatorname{size}^{25,26}$. However, there is no clear explanation for this observation.

\section{Diet, physical activity, and body fatness in early adulthood}

\section{Diet}

A role for some specific nutrients in BC etiology has been suggested, based on associations reported in epidemiological studies and further supported by a biological plausibility, related to antioxidant properties of selected nutrients, influence on epigenetic processes, DNA repair, DNA adducts, inflammation, regulation of gene expression, stimulation of growth factors, or impact on circulating levels of endogenous hormones. Energy balance, the interplay of caloric intake, physical activity, $\mathrm{BMI}$, and metabolic rate are other important factors that may impact BC development ${ }^{27}$.

\section{Fatty acids}

Some epidemiological studies indicate that rather than total fat intake, subtypes of fatty acids could be more determinant and diversely affect BC risk. However, most analyses have focused on postmenopausal women ${ }^{28}$. Data on premenopausal BC are still sparse.

A potential link between dietary fat and $B C$ has been a focus of intense research; however, overall findings to date are conflicting ${ }^{29-31}$. A high dietary intake of cis-monounsaturated fat, such as olive oil ${ }^{32}$ or longchain n-3 PUFAs from marine sources (fatty fish such as salmon, sardine, and mackerel) ${ }^{28}$ may reduce the $\mathrm{BC}$ risk. Conversely, a positive association has been reported between dietary intake of saturated fatty acids (SFA), such as butter and fat in meat and $\mathrm{ER}^{+}$ $\mathrm{BC}^{33}$. However, overall data on specific fatty acids are still discrepant. Epidemiological data on biomarkers of exposure to fatty acids and $B C$ risk are also limited. Meta-analyses of prospective and case-control studies have suggested a protective effect of $n-3$ PUFA on $B C$ risk $^{28}$, while some SFA and monounsaturated fats have been associated with an increased risk of $\mathrm{BC}^{34}$. One prospective study showed a significant association between high blood levels of industrial transfatty acids, found in industrially processed foods, and increased risk of $\mathrm{BC}^{35}$. However, in general, prospective studies have not shown clear associations between patterns of fatty acids and risk of BC, overall and by hormonal receptor status ${ }^{36}$. More epidemiological prospective studies that integrate reliable biomarkers of exposure to fatty acids are needed to investigate further the contribution of different types of fatty acids to the etiology of $\mathrm{BC}$, overall and by hormone receptor subtypes.

Due to their suspected preventive effect on BC, n-3 PUFA may be a good target for nutritional prevention of $\mathrm{BC}$; however, little is known regarding the relationship between $n-3$ PUFA intake and BC risk among young women in less developed countries. In a population-based case-control study conducted in Mexico, a decreased risk of $B C$ was significantly associated with increasing n-3 PUFA intake and the ratio of $\mathrm{N}-3 / \mathrm{N}-6$ PUFA in premenopausal women. This effect was present in obese women, but not in normal weight or overweight women ${ }^{37}$. These data suggested that obesity status may affect the association between n-3 PUFA intake and $B C$ risk. In addition, the underlying mechanisms may be related to decreased inflammation and 
improved adipokine and estrogen levels induced by $n-3$ PUFA in adipose tissue in obese women.

\section{Carbohydrates, Gl, and GL}

Carbohydrates and carbohydrate quality could potentially influence $B C$ risk by affecting insulin resistance and plasma levels of insulin and glucose ${ }^{38}$.

Many factors influence how rapidly carbohydrates are digested and absorbed and hence what their glycemic and insulinemic effects will be ${ }^{39}$. Refined carbohydrate, such as pure sugar, is rapidly absorbed. This physiological response of carbohydrates can be quantified by the $\mathrm{Gl}$, which compares the plasma glucose response to specific foods with that induced by the same amount of a standard carbohydrate source, usually white bread or pure glucose $\mathrm{e}^{40}$. The $\mathrm{Gl}$ is, therefore, a measure of carbohydrate quality. However, both the quality and quantity of dietary carbohydrates need to be considered in relation to metabolic effects; the GL of a specific food, calculated as the product of $\mathrm{Gl}$ and the amount of dietary carbohydrates in a food item, has been proposed as a global indicator of the glucose response and insulin demand induced by a serving of food $^{41}$.

A recent meta-analysis of prospective studies reported a significant positive association between Gl and $\mathrm{BC}$ risk. In subgroup analyses by menopausal status, the pooled relative risk (RR) was 1.05 (95\% Cl: $0.83-1.33$ ) for $\mathrm{Gl}$ and 1.28 ( $95 \% \mathrm{Cl}: 0.94-1.75$ ) for $\mathrm{GL}$ among premenopausal women ${ }^{42}$. Supporting this hypothesis, data from Mexico, where carbohydrates account for close to $64 \%$ of caloric intake for the population, showed a strong positive association between carbohydrate intake as well as GL and BC among premenopausal women ${ }^{43}$. High intake of refined carbohydrates may have stronger associations with $\mathrm{BC}$ risk in populations genetically susceptible to insulin resistance, such as in Mexico, particularly when combined with obesity and physical inactivity ${ }^{44}$.

\section{$B$ vitamins, folate}

Folate, originating mainly from green leafy vegetables and fruits, is an important $B$ vitamin required for DNA synthesis, and it is also involved in the methionine metabolic pathway, which is crucial for DNA methylation. Thus, one-carbon metabolism can impact both genetic and epigenetic procarcinogenic processes, and these biological roles potentially make folate and other related B vitamins significant in cancer prevention $^{45}$.

The associations between $B$ vitamins and $B C$ have been extensively studied in high-income countries, and the associations are complex. Epidemiological studies of the association between folate intake, estimated through questionnaires, and $B C$ risk have provided mixed results ${ }^{46}$. Protective effects have been observed in populations with low folate status, in which vitamin supplementation is infrequent ${ }^{47}$, or in women with increased risk for BC because of high alcohol intake. In the EPIC study, a $14 \%$ reduction in $\mathrm{BC}$ risk was observed when comparing the highest with the lowest dietary folate tertiles in women having a high (> 12 alcoholic drinks/week) alcohol intake $(95 \% \mathrm{Cl}:-25 \text { to }-2)^{48}$. However, in a further analysis based on folate plasma levels, overall, folate and vitamin B12 status were not clearly associated with premenopausal BC risk ${ }^{49}$. The risk did seem to increase somewhat for women who had higher vitamin B12 levels and either low plasma folate or increased alcohol consumption. This may involve nutrient-nutrient or gene-nutrient interactions, such as changes in DNA methylation, which require further investigation ${ }^{49}$. As for other dietary components, additional factors may impact the relationship between folate intake and $\mathrm{BC}$ risk, such as alcohol intake and polymorphisms in methylenetetrahydrofolate reductase, which codes for a key one-carbon metabolizing protein. Further, the impact of folate may be related with the tumor type.

Data from the National Mexican Health Survey show that folate intake in Mexican women is low as well as folate blood level ${ }^{50}$. In a population-based, case-control study conducted in Mexico, folate and vitamin B6 were not significantly related to premenopausal BC (odds ratio [OR]: 0.73 [95\% Cl: $0.46-1.27$ ] and 0.76 [95\% Cl: 0.46-0.99], respectively); however, vitamin B12 was inversely related to BC (OR: 0.54; $95 \%$ Cl: $0.29-0.99)^{47}$.

\section{Vitamin D}

Vitamin $\mathrm{D}$ is important in many physiological processes. Vitamin $D$ is predominantly synthesized in the skin from cholesterol through exposure to ultraviolet $B$ radiation, and deficiency because of low sunlight is not easily corrected by dietary intake alone in the absence of supplementation. A growing body of 
research currently supports vitamin D deficiency as a risk factor for $\mathrm{BC}^{51}$. The protective effects of vitamin $D$ have been shown to function mainly through the vitamin D receptor present in breast cells. Some studies have suggested that the effect of vitamin $D$ in the breast might result from its effect on the insulin growth factor signaling pathway ${ }^{52}$. However, epidemiological studies have had inconsistent results. In a recent large meta-analysis, the pooled RR of BC for the highest (> $500 \mathrm{IU} /$ day, mean) versus lowest categories of vitamin D intake ( $<148 \mathrm{IU} /$ day, mean) was 0.95 (95\% Cl: 0.88-1.01), with no significant heterogeneity among the studies. The pooled RR of BC for the highest ( $>31 \mathrm{ng} / \mathrm{ml}$, mean) versus lowest categories of 25-hydroxy vitamin D levels $(<18 \mathrm{ng} / \mathrm{ml}$, mean) provided similar results ${ }^{53}$. In addition, a recent review and meta-analysis of randomized controlled trials suggested that vitamin $\mathrm{D}$ supplementation was not associated with a reduced risk of $\mathrm{BC}^{54}$.

In contrast, among premenopausal Mexican women, a population with vitamin $\mathrm{D}$ deficiency, the protective effect of vitamin $D$ was observed. Mexican women with serum vitamin $D$ levels $<20 \mathrm{ng} / \mathrm{ml}$ (defined as cutoff value for deficiency) had a higher risk of $B C$ than women with a level $>20 \mathrm{ng} / \mathrm{ml}$. In addition, a significant inverse dose-response was observed at higher levels of vitamin $\mathrm{D}$ associated with lower risk of $\mathrm{BC}^{55}$. Similarly, higher serum levels of vitamin $D(>27.3 \mathrm{ng} / \mathrm{ml}$ ) were significantly inversely associated with lower percent mammographic density among young Mexican women with $\mathrm{BMl}<27 \mathrm{~kg} / \mathrm{m}^{2}$ (median value), suggesting that some groups of women may benefit from vitamin $D$ supplementation $^{56}$. Further research is needed to determine the amount of vitamin $D$ necessary to achieve a protective benefit against BC.

\section{Carotenoids}

A systematic review and meta-analysis of prospective studies of dietary intake and blood concentrations of carotenoids and BC risk reported stronger associations with blood concentrations than with dietary estimates, probably because the measurement error in the dietary assessment of carotenoid intake from fruit (such as mango, orange, tangerine, melon, and papaya) and vegetables (such as carrots, pumpkin, tomato, kale, and sweet potato) may have attenuated associations with $\mathrm{BC}$ risk $^{57}$. Of the six dietary carotenoids assessed, only intake of $\beta$-carotene was significantly associated with a reduced $B C$ risk. In contrast, blood concentrations of total carotenoids, $\beta$-carotene, $\alpha$-carotene, and lutein were inversely associated with BC risk. However, no specific estimation was provided for premenopausal $B C$ risk. In a recent report, an inverse association between plasma carotenoids and risk of premalignant breast diseases was found in younger women, consistent with inverse associations reported for invasive $\mathrm{BC}^{11}$. Carotenoids may play a role in $\mathrm{BC}$ early development. The relative levels of the different types of carotenoids are important to take into account as well as a potential influence from other lifestyle factors ${ }^{58}$.

\section{Soy}

Soy foods and soy products are rich in phytoestrogens, naturally occurring hormone-like compounds with weak estrogenic effects. Despite inconsistencies in the available data, an inverse association between soy food consumption and BC is likely ${ }^{59}$. However, it seems that this association is more obvious in Asian populations where the consumption of soy is higher than in Western populations ${ }^{59}$. In a recent meta-analysis, no effect was observed among premenopausal BC. In addition, soy consumption during childhood and adolescence might be the most relevant period, and only studies in Asian populations have evaluated this association ${ }^{18}$. Thus, the impact of soy foods and soy products may depend on genetics, prior soy intake, timing of exposure, and level of soy intake.

\section{Fiber}

The WCRF review panel concluded that there is an insufficient level of evidence for the association between dietary fiber and BC risk $^{9}$. A systematic review and meta-analysis of prospective studies in high-income countries showed a significant inverse association between dietary fiber intake and risk of $\mathrm{BC}^{60}$. The estimate suggested a decrease of $5 \%$ in the risk of $\mathrm{BC}$ per $10 \mathrm{~g} /$ day $(95 \% \mathrm{Cl}:-9$ to -2 ). Dietary fiber source may be important since a recent prospective study showed that BC risk was inversely associated with intakes of dietary fiber from vegetables, but not with fiber from fruit, cereals, or other dietary sources ${ }^{61}$. Fiber intake has also been linked to playing a role in modulating the adverse effect of alcohol consumption for fiber from vegetable sources ${ }^{62}$. It is unclear what specific biological mechanisms may underlie observed differences in associations of vegetable versus fruit and cereal fibers with BC. Alcohol has 
been shown to increase hormone levels, and a reduction of circulating hormones has been observed with fiber intake. Fiber may bind estrogens in the colon and increase excretion. Fiber may also reduce hydrolysis of conjugated estrogens, resulting in less absorption. The role of phytochemicals such as antioxidants and phytoestrogen in glycemic/insulin control has also been invoked ${ }^{62}$. Other dietary factors may be involved, as a combination of low-fat and high-fiber intake was associated with a significant reduction of risk of $B C$ in premenopausal women ${ }^{61}$. In Mexico, results from a hospital-based case-control study showed a lower risk of $B C$ in premenopausal women with a higher intake of total fiber ${ }^{63}$. In a population-based case-control study, fiber intake modulated the adverse effect of carbohydrate on the risk of BC. The relative risk $(95 \% \mathrm{Cl})$ of $\mathrm{BC}$ in the highest quartile of sucrose intake was 2.37 (1.58-3.55) among women who consumed low levels of insoluble fibers ( $\leq 22.2 \mathrm{~g} /$ day) and was 1.07 (0.65-1.77) among women who consumed high levels of insoluble fibers ( $>22 \mathrm{~g} /$ day). Similar results were observed for fructose and glucose intakes ${ }^{43}$.

\section{Alcohol}

The only dietary factor identified by the WCRF analysis for which there was strong evidence (probable) for its association with increased BC risk is alcohol consumption ${ }^{9,64}$. An overwhelming number of epidemiological studies provide support for the positive relationship between alcohol and $\mathrm{BC}$ risk ${ }^{65}$. A dose-response meta-analysis reported that an increase in alcohol consumption of $10 \mathrm{~g}$ of ethanol per day was associated with increased risks for all $E R^{+}, E R^{-}, E R^{+} P R^{+}$, and $E R^{+} \mathrm{PR}^{-}$, but not $\mathrm{ER}^{-} \mathrm{PR}^{-}$tumors ${ }^{66}$. However, other studies have reported an increase in $E R^{-} / \mathrm{PR}^{-}$tumors as well, and the evidence suggests that alcohol may increase the risk of premenopausal BC through different pathways ${ }^{67}$. In a large case-control study conducted in Mexico, over one-half ( $57 \%$ ) of cases and less than one-half of controls (45\%) reported any lifetime alcohol consumption. Compared with never-drinkers, women reporting ever drinking had a greater risk of BC (adjusted OR: 1.25; $95 \% \mathrm{Cl}: 0.99-1.58$ ). There was evidence for an interaction in the association between ever consuming any alcohol, BC, and folate intake (for interaction $p=0.04)$, suggesting that women with lower folate intake had higher odds of BC (OR: 1.99; 95\% Cl: 1.26-3.16) compared to women with higher folate intake (OR: 1.12; $95 \% \mathrm{Cl}$ : 0.69-1.83). Models were adjusted for menopausal status; therefore, there were no results specific for young women. However, based on international data, it is very likely that alcohol consumption has a strong adverse effect on $B C$ among young women ${ }^{68}$.

\section{Dietary patterns}

In general, the dietary patterns investigated are a prudent or healthy dietary pattern (high in vegetables and/or fruits, poultry, fish, low-fat dairy, and/or whole grains) as compared to the Western diet or so-called unhealthy diet (red or processed meats, refined grains, sweets, and/or high-fat dairy). In a review of the literature by the WCRF, there was no convincing evidence that a prudent pattern conferred protection from $\mathrm{BC}^{9}$. However, relatively few prospective studies have explored dietary patterns in relation to risk of $B C$ in premenopausal women and results are, in general, non-significant, in part because of the lack of power of these studies, which included a small number of premenopausal cancer cases. The EPIC-Potsdam study found that a dietary pattern characterized by highfat foods was associated with increased risk of $B C$ in both pre- and postmenopausal women ${ }^{69}$. In a recent meta-analysis, Brennan et al. ${ }^{70}$ observed a small protective effect of a "prudent dietary pattern" on BC risk. However, when data were stratified by menopausal status, results were non-significant. A recent study in Mexico supports the role of western dietary pattern in the serum concentration of free estradiol ${ }^{71}$, in particular, a diet with high content of chicken eggs and meat, which can therefore increase the risk of BC.

\section{Physical activity}

Regular physical activity reduces the risk of premenopausal BC; however, the impact appears to be less than in postmenopausal women. Multiple interrelated biological pathways are likely to be involved, including adiposity, sex hormones, insulin resistance, adipokines, and chronic inflammation ${ }^{8}$. In a large meta-analysis of prospective studies, overall, dose-response suggests that the risk of $\mathrm{BC}$ decreased by $3 \%(95 \% \mathrm{Cl}:-5$ to -2$)$ for every 10 metabolic equivalent of task-hours/week increment in recreational activity (roughly equivalent to $4 \mathrm{~h}$ /week of walking at 2 miles/h) ${ }^{24}$. In a more recent meta-analysis including 49 studies among premenopausal women, a statistically significant $20 \%$ lower risk for women in the highest versus lowest 
categories of moderate/vigorous recreational activity ( $95 \% \mathrm{Cl}:-26$ to -13 ) was observed. Effects were distinct by $\mathrm{BC}$ subtypes with a significant effect among $\mathrm{ER}^{+} / \mathrm{PR}^{+}$and $\mathrm{ER}^{-} / \mathrm{PR}^{-}$or HER2 $2^{-}$and $\mathrm{p} 53^{-} \mathrm{BC}(40 \%$ and $50 \%$ lower risks of $\mathrm{ER}^{-} / \mathrm{PR}^{-}$and $\mathrm{ER}^{+} / \mathrm{PR}^{+}$breast tumors, respectively, comparing the most versus the least active women ${ }^{72}$. Physical activity at each stage of life from adolescence onward provides a benefit, but sustained activity throughout life may provide the greatest benefit ${ }^{14}$. In the NHS II, for example, a reduced risk of premenopausal BC was most apparent among women who engaged in high levels of activity during both youth (ages 12-22 years) and adulthood ${ }^{12}$, consistent with earlier studies ${ }^{73}$.

\section{Healthy lifestyle index}

Healthy lifestyle index is an interesting approach to evaluate the potential decrease of $\mathrm{BC}$ risk associated with a healthy lifestyle and provides an overall estimation of how much BC could be avoided with lifestyle modifications. In a study conducted in Mexico ${ }^{74}$, adherence to a healthy lifestyle, including moderate and/or vigorous intensity physical activity, low consumption of fat, processed foods, refined cereals, complex sugars, and the avoidance of tobacco smoking and alcohol consumption, was associated with a protective effect in premenopausal women (50\% decrease in risk; $95 \%$ $\mathrm{Cl}:-71$ to -16$)$ when comparing the highest to the lowest quartiles.

\section{Body fatness}

Overweight and obesity have been associated with a decreased risk of BC in premenopausal women ${ }^{26}$. In a meta-analysis including 20 studies, Renehan et al. ${ }^{75}$ reported an overall decrease in risk of $8 \%(95 \% \mathrm{Cl}:-12$ to -3 ) for each increment of $5 \mathrm{~kg} / \mathrm{m}^{2}$ in BMI. While $\mathrm{BMI}$ is a valid parameter for general adiposity, it does not reflect the visceral fat deposit and WC, and WHR provides a better proxy of abdominal adipose tissue, which appears to be more metabolically active than peripheral adipose tissue ${ }^{25,76}$. In a recent meta-analysis, each 0.1 unit higher WHR was related to $8 \%$ higher risk of premenopausal $\mathrm{BC}^{77}$. Recent data from the NHS II reported a positive association between WC, WHR, and premenopausal BC. This association was stronger for $\mathrm{ER}^{-} / \mathrm{PR}^{-}$tumors ${ }^{78}$. Among Hispanic women living in the USA, high BMI at 30 years of age was associated to a decrease of premenopausal BC (64\% decrease in risk; $95 \% \mathrm{Cl}:-75 \%$ to $-26 \%$ for $\mathrm{BMl}>30$ vs. $\left.<25 \mathrm{~kg} / \mathrm{m}^{2}\right)^{79}$. In a more recent study, with specific analysis of hormonal receptor status, young adult age and current $\mathrm{BMI}$ were inversely associated with the risk of $\mathrm{BC}$ among $\mathrm{ER}^{+} / \mathrm{PR}^{+}$and $\mathrm{ER}^{-} / \mathrm{PR}^{-} \mathrm{BC}$ of close to $50 \%$ among women with elevated young-adult BMI and current obesity. However, analyses of WC and WHR suggest a positive association with $B C$ risk (close to doubling in risk when comparing $W C<79.5$ versus $>91.4$ and for $\mathrm{WHR}<0.77$ versus $>0.83)^{80}$.

Weight gain could have an important impact on BC. In the NHS II, weight gain from baseline to current weight (over 4 years) was related to an increased risk in premenopausal BC (38\% increase; $95 \% \mathrm{Cl}$ : 13-69) for a 4-year weight gain of $\geq 15 \mathrm{lb}$ versus no change $(\leq 5 \mathrm{lb})$. The association was stronger for $\mathrm{ER}^{+} / \mathrm{PR}^{-}$ and $E R^{-} / P^{-} R^{-} C^{81}$. The effect was significantly stronger among those women who were normal weight at baseline (RR 1.65 vs. 1.02 for $25 \mathrm{lb}$ weight change). In accordance with these results, in a study conducted among Mexican premenopausal women, women were asked to select the silhouette that best represented their body shape (using six pictograms representing body shapes ranging from lean to large) at six different ages: Childhood (aged 6-11 years), adolescence (aged 12-18 years), aged 18-20 years, before first pregnancy, aged 25-35 years, and at current age. A strong increase in silhouette from childhood to current silhouette was associated to an increased risk of BC increase (OR: $1.65 ; 95 \% \mathrm{Cl}: 0.98-2.75$ ). Still, the association of obesity with premenopausal $\mathrm{BC}$ remains unclear. While obesity has been related to anovulatory cycles, reducing exposure to hormone-dependent, tumor-promoting growth ${ }^{82}$, obesity has been associated to inflammation and dysregulated metabolism ${ }^{76,83}$ that can promote tumor growth. In addition, abdominal fat distribution (subcutaneous vs. visceral fat) may play an important role and needs to be further studied.

\section{Breastfeeding}

Breastfeeding has been classified by WCRF as a protective factor for BC in both pre- and postmenopausal women. Research by the International Collaborative Group on Hormonal Factors in BC, based on individual data from over 50,000 women with $B C$ in 30 different countries, has shown that breastfeeding has a protective effect estimated at a $4.3 \%$ risk reduction for every 
12 months of cumulative breastfeeding (in addition to an estimated $7 \%$ reduction in risk for each birth) in both pre- and post-menopausal women ${ }^{84}$. The meta-analysis performed by the Continuous Update Project of the WCRF estimated at $2 \%$ the decreased $B C$ risk (pooled OR: 0.98; 95\% Cl: 0.97-0.98) for an increase of 5 months of total breastfeeding ${ }^{64}$. Relatively few studies made the distinction between exclusive breastfeeding and mixed feeding. A systematic review and meta-analysis including studies until 2015 concluded that exclusive breastfeeding reduced the risk by $28 \%$ compared to parous women who had never breastfed. Any mode of breastfeeding in premenopausal women was related to a reduction of $14 \%$. In a recent meta-analysis, ever breastfeeding was significantly associated with a $10 \%$ reduced risk of $\mathrm{ER}^{-} / \mathrm{PR}^{-} \mathrm{BC}$ and a $20 \%$ reduced risk in TN BC, which are more frequent in young women. In addition, systematic reviews of risk factors of BC in BRCA1 and BRCA2 carriers showed an inverse association between breastfeeding and $B C$ in BRCA1 carriers ${ }^{85}$, which are more likely to develop $E R^{-} / \mathrm{PR}^{-}$and $\mathrm{TN} \mathrm{BC}$ than in $\mathrm{BRCA} 2^{86}$. Several mechanisms have been invoked ${ }^{87}$ : Differentiation of breast epithelium, making the cells less susceptible to malignant transformation, and prolonged breastfeeding, which may lower the periodic influence of estrogen/ progesterone on breast tissue and thus protect against BC. In addition, the strong exfoliation of breast tissue during lactation and the massive epithelial apoptosis at the end of breastfeeding could contribute to decrease the risk of cancer by excreting cells with initial DNA damage from the breast ductal tissue. These results are particularly important to young women for whom aggressive tumors are more likely and less responsive to treatment.

\section{DISCUSSION}

$B C$ in young women has aggressive biological characteristics and poorer outcome than BC in older women. There is a growing body of evidence that healthy lifestyle starting early on during childhood and adolescence may have an important impact on the risk of premenopausal BC. Given the public health importance of $B C$ in young women, and to fight its rise in less-developed countries where nutritional transition is occurring rapidly; it is of utmost importance to identify further modifiable factors associated to BC. Harmonization of study methodology and the stratification of BC by specific characteristics of tumors need to be considered since specific risk factors might be more particularly associated with the promotion of, or protection from, a defined type of BC. The use of specific biomarkers of nutrient intake and metabolic pathways as well as genetic markers may clarify the mechanisms by which diet, physical activity, and body fatness affect the risk of premenopausal BC. Efforts ought to be placed on advising women to follow a healthy diet, practice daily physical activity, avoid gaining weight in adult life and breastfeed their child.

\section{ACKNOWLEDGMENTS}

The authors thank Irma Soyachi for her support in the preparation of this manuscript.

\section{REFERENCES}

1. Ferlay J, Soerjomataram I, Dikshit R, Eser S, Mathers C, Rebelo M, et al. Cancer incidence and mortality worldwide: Sources, methods and major patterns in GLOBOCAN 2012. Int J Cancer. 2015;136:E359-86.

2. Villarreal-Garza C, Aguila C, Magallanes-Hoyos MC, Mohar A, Bargalló E. Breast cancer in young women in Latin America: An unmet, growing burden. Oncologist. 2013;18:26-34.

3. Dunn BK, Agurs-Collins T, Browne D, Lubet R, Johnson KA. Health disparities in breast cancer: Biology meets socioeconomic status. Breast Cancer Res Treat. 2010;121:281-92.

4. Narod SA. Breast cancer in young women. Nat Rev Clin Oncol. 2012;9:460-70.

5. Lee $\mathrm{HB}, \mathrm{Han} W$. Unique features of young age breast cancer and its management. J Breast Cancer. 2014;17:301-7.

6. Assi HA, Khoury KE, Dbouk H, Khalil LE, Mouhieddine TH, El Saghir NS. Epidemiology and prognosis of breast cancer in young women. J Thorac Dis. 2013;5 Suppl 1:S2-8.

7. Malone KE, Daling JR, Neal C, Suter NM, O'Brien C, CushingHaugen $K$, et al. Frequency of BRCA1/BRCA2 mutations in a population-based sample of young breast carcinoma cases. Cancer. 2000;88:1393-402.

8. Friedenreich CM. Physical activity and breast cancer: Review of the epidemiologic evidence and biologic mechanisms. Recent Results Cancer Res. 2011;188:125-39.

9. World Cancer Research Fund/American Institute for Cancer Research. Continuous Update Project Report/Breast cancer report. Food, Nutrition, Physical Activity, and the Prevention; 2017.

10. Institute of Medicine. Breast Cancer and the Environment: A Life Course Approach. Washington, DC: The National Academies Press; 2012.

11. Colditz GA, Bohlke K. Priorities for the primary prevention of breast cancer. CA Cancer J Clin. 2014;64:186-94.

12. Maruti SS, Willett WC, Feskanich D, Rosner B, Colditz GA. A prospective study of age-specific physical activity and premenopausal breast cancer. J Natl Cancer Inst. 2008;100:728-37.

13. Matthews CE, Shu XO, Jin F, Dai Q, Hebert JR, Ruan ZX, et al. Lifetime physical activity and breast cancer risk in the Shanghai breast cancer study. Br J Cancer. 2001;84:994-1001.

14. Lynch BM, Neilson HK, Friedenreich CM. Physical activity and breast cancer prevention. Recent Results Cancer Res. 2011;186:13-42.

15. Liu Y, Colditz GA, Rosner B, Berkey CS, Collins LC, Schnitt S], et al. Alcohol intake between menarche and first pregnancy: A prospective study of breast cancer risk. J Natl Cancer Inst. 2013;105:1571-8. 
16. Chen WY, Rosner B, Hankinson SE, Colditz GA, Willett WC. Moderate alcohol consumption during adult life, drinking patterns, and breast cancer risk. JAMA. 2011;306:1884-90.

17. Romieu I, Scoccianti C, Chajès V, de Batlle J, Biessy C, Dossus L, et al. Alcohol intake and breast cancer in the European prospective investigation into cancer and nutrition. Int J Cancer. 2015;137:1921-30.

18. Korde LA, Wu AH, Fears T, Nomura AM, West DW, Kolonel LN, et al. Childhood soy intake and breast cancer risk in Asian American women. Cancer Epidemiol Biomarkers Prev. 2009; 18:1050-9.

19. Lee SA, Shu XO, Li H, Yang G, Cai H, Wen W, et al. Adolescent and adult soy food intake and breast cancer risk: Results from the shanghai women's health study. Am J Clin Nutr. 2009;89:1920-6

20. Linos E, Willett WC, Cho E, Frazier L. Adolescent diet in relation to breast cancer risk among premenopausal women. Cancer Epidemiol Biomarkers Prev. 2010;19:689-96.

21. Linos E, Willett WC, Cho E, Colditz G, Frazier LA. Red meat consumption during adolescence among premenopausal women and risk of breast cancer. Cancer Epidemiol Biomarkers Prev. 2008;17:2146-51

22. McCullough ML, Willett WC. Evaluating adherence to recommended diets in adults: The Alternate Healthy Eating Index. Public Health Nutr. 2006;9:152-7.

23. Harris HR, Willett WC, Vaidya RL, Michels KB. Adolescent dietary patterns and premenopausal breast cancer incidence. Carcinogenesis. 2016;37:376-84.

24. Wu Y, Zhang D, Kang S. Physical activity and risk of breast cancer: A meta-analysis of prospective studies. Breast Cancer Res Treat. 2013;137:869-82.

25. Fortner RT, Katzke V, Kühn T, Kaaks R. Obesity and breast cancer. Recent Results Cancer Res. 2016;208:43-65

26. Amadou A, Hainaut P, Romieu I. Role of obesity in the risk of breast cancer: Lessons from anthropometry. J Oncol. 2013;2013:906495

27. Chajès V, Romieu I. Nutrition and breast cancer. Maturitas. 2014;77:7-11.

28. Zheng JS, Hu XJ, Zhao YM, Yang J, Li D. Intake of fish and marine $\mathrm{n}-3$ polyunsaturated fatty acids and risk of breast cancer: Metaanalysis of data from 21 independent prospective cohort studies. BMJ. 2013;346:f3706.

29. Turner LB. A meta-analysis of fat intake, reproduction, and breast cancer risk: An evolutionary perspective. Am J Hum Biol. 2011:23:601-8

30. Thiébaut AC, Kipnis V, Chang SC, Subar AF, Thompson FE, Rosenberg PS, et al. Dietary fat and postmenopausal invasive breast cancer in the National institutes of health-AARP Diet and Health Study cohort. J Natl Cancer Inst. 2007; 99:451-62

31. Prentice RL, Caan B, Chlebowski RT, Patterson R, Kuller LH, Ockene $\mathrm{JK}$, et al. Low-fat dietary pattern and risk of invasive breast cancer: The Women's health initiative randomized controlled dietary modification trial. JAMA. 2006;295:629-42.

32. Voorrips LE, Brants HA, Kardinaal AF, Hiddink GJ, van den Brandt PA, Goldbohm RA. Intake of conjugated linoleic acid, fat, and other fatty acids in relation to postmenopausal breast cancer: The Netherlands Cohort Study on Diet and Cancer. Am J Clin Nutr. 2002;76:873-82.

33. Sieri S, Chiodini P, Agnoli C, Pala V, Berrino F, Trichopoulou A, et al. Dietary fat intake and development of specific breast cancer subtypes. J Natl Cancer Inst. 2014;106. pii: dju068.

34. Saadatian-Elahi M, Norat T, Goudable J, Riboli E. Biomarkers of dietary fatty acid intake and the risk of breast cancer: $A$ meta-analysis. Int J Cancer. 2004:111:584-91.

35. Chajès V, Thiébaut AC, Rotival $M$, Gauthier $E$, Maillard V, Boutron-Ruault $M C$, et al. Association between serum trans-monounsaturated fatty acids and breast cancer risk in the E3N-EPIC Study. Am J Epidemiol. 2008:167:1312-20.

36. Schmidt JA, Gorst-Rasmussen A, Nyström PW, Christensen JH, Schmidt EB, Dethlefsen C, et al. Baseline patterns of adipose tissue fatty acids and long-term risk of breast cancer:
A case-cohort study in the Danish cohort Diet, Cancer and Health. Eur J Clin Nutr. 2014;68:1088-94.

37. Chajès V, Torres-Mejía G, Biessy C, Ortega-Olvera C, AngelesLlerenas A, Ferrari P, et al. Omega-3 and omega- 6 polyunsaturated fatty acid intakes and the risk of breast cancer in Mexican women: Impact of obesity status. Cancer Epidemiol Biomarkers Prev. 2012;21:319-26.

38. Michels KB, Mohllajee AP, Roset-Bahmanyar E, Beehler GP, Moysich KB. Diet and breast cancer: A review of the prospective observational studies. Cancer. 2007;109 12 Suppl:2712-49.

39. World Health Organization, Food and Agriculture Organization of the United Nations. Carbohydrates in Human Nutrition. Report of a Joint FAO/WHO Expert Consultation; 1998.

40. Liu S, Willett WC, Stampfer MJ, Hu FB, Franz M, Sampson L, et al. A prospective study of dietary glycemic load, carbohydrate intake, and risk of coronary heart disease in US women. Am J Clin Nutr. 2000;71:1455-61.

41. Wolever TM, Jenkins DJ. The use of the glycemic index in predicting the blood glucose response to mixed meals. Am J Clin Nutr. 1986;43:167-72

42. Choi Y, Giovannucci E, Lee JE. Glycaemic index and glycaemic load in relation to risk of diabetes-related cancers: A meta-analysis. Br J Nutr. 2012;108:1934-47.

43. Romieu I, Lazcano-Ponce E, Sanchez-Zamorano LM, Willett W, Hernandez-Avila M. Carbohydrates and the risk of breast cancer among Mexican women. Cancer Epidemiol Biomarkers Prev. 2004;13:1283-9.

44. Gómez LM, Hernández-Prado B, Morales MC, Shamah-Levy T. Physical activity and overweight/obesity in adult Mexican population: The Mexican national health and nutrition survey 2006. Salud Publica Mex. 2009;51:S621-9.

45. Teegarden $D$, Romieu I, Lelièvre SA. Redefining the impact of nutrition on breast cancer incidence: Is epigenetics involved? Nutr Res Rev. 2012:25:68-95.

46. $\mathrm{Xu} X, \mathrm{C}$ en J. One-carbon metabolism and breast cancer: An epidemiological perspective. J Genet Genomics. 2009; 36:203-14.

47. Lajous M, Lazcano-Ponce E, Hernandez-Avila M, Willett W Romieu I. Folate, vitamin $B(6)$, and vitamin $B(12)$ intake and the risk of breast cancer among Mexican women. Cancer Epidemiol Biomarkers Prev. 2006;15:443-8.

48. de Batlle J, Ferrari P, Chajes V, Park JY, Slimani N, McKenzie F, et al. Dietary folate intake and breast cancer risk: European prospective investigation into cancer and nutrition. J Natl Cancer Inst. 2014:107:367.

49. Matejcic M, de Batlle J, Ricci C, Biessy C, Perrier F, Huybrechts I, et al. Biomarkers of folate and vitamin B12 and breast cancer risk: Report from the EPIC cohort. Int JCancer. 2017;140:1246-59.

50. Pedroza-Tobías A, Hernández-Barrera L, López-Olmedo N García-Guerra A, Rodríguez-Ramírez S, Ramírez-Silva I, et al. Usual vitamin intakes by Mexican populations. J Nutr. 2016:146:1866S-73.

51. Shao T, Klein P, Grossbard ML Vitamin D and breast cancer. Oncologist. 2012;17:36-45.

52. Khan QJ, Kimler BF, Fabian CJ. The relationship between vitamin $\mathrm{D}$ and breast cancer incidence and natural history. Curr Oncol Rep. 2010;12:136-42.

53. Kim Y, Je Y. Vitamin D intake, blood $25(\mathrm{OH}) \mathrm{D}$ levels, and breast cancer risk or mortality: A meta-analysis. Br J Cancer. 2014; 110:2772-84.

54. Sperati F, Vici P, Maugeri-Saccà M, Stranges S, Santesso N, Mariani L, et al. Vitamin D supplementation and breast cancer prevention: A systematic review and meta-analysis of randomized clinical trials. PLoS One. 2013;8:e69269.

55. Fedirko V, Torres-Mejía G, Ortega-Olvera C, Biessy C, AngelesLlerenas A, Lazcano-Ponce E, et al. Serum 25-hydroxyvitamin D and risk of breast cancer: Results of a large population-based case-control study in Mexican women. Cancer Causes Control. 2012;23:1149-62

56. Amadou A, Biessy C, Rinaldi S, Fedirko V, Assi N, Lajous M, et al. Serum 25-hydroxyvitamin D3 and mammography density among mexican women. PLoS One. 2016;11:e0161686. 
57. Aune D, Chan DS, Vieira AR, Navarro Rosenblatt DA, Vieira R, Greenwood DC, et al. Dietary compared with blood concentrations of carotenoids and breast cancer risk: A systematic review and meta-analysis of prospective studies. Am J Clin Nutr. 2012;96:356-73.

58. Cohen K, Liu Y, Luo J, Appleton CM, Colditz GA. Plasma carotenoids and the risk of premalignant breast disease in women aged 50 and younger: A nested case-control study. Breast Cancer Res Treat. 2017;162:571-80.

59. Mourouti N, Panagiotakos DB Soy food consumption and breast cancer. Maturitas. 2013;76:118-22.

60. Aune D, Chan DS, Greenwood DC, Vieira AR, Rosenblatt DA, Vieira R, et al. Dietary fiber and breast cancer risk: A systematic review and meta-analysis of prospective studies. Ann Oncol. 2012;23:1394-402.

61. Ferrari P, Rinaldi S, Jenab M, Lukanova A, Olsen A, Tjønneland A, et al. Dietary fiber intake and risk of hormonal receptor-defined breast cancer in the european prospective investigation into cancer and nutrition study. Am J Clin Nutr. 2013;97:344-53.

62. Romieu I, Ferrari P, Chajès V, de Batlle J, Biessy C, Scoccianti C, et al. Fiber intake modulates the association of alcohol intake with breast cancer. Int J Cancer. 2017;140:316-21.

63. Bonilla-Fernández $P$, López-Cervantes $M$, Torres-Sánchez LE, Tortolero-Luna G, López-Carrillo L. Nutritional factors and breast cancer in Mexico. Nutr Cancer. 2003;45:148-55.

64. Norat T, Chan D, Lau R, Aune D, Vieira R. The Associations Between Food, Nutrition and Physical Activity and the Risk of Colorectal Cancer. London: World Cancer Research Fund/ American Institute for Cancer Research, WCRF/AICR Systematic Literature Review Continuous Update Project Report; 2010.

65. Brooks PJ, Zakhari S. Moderate alcohol consumption and breast cancer in women: from epidemiology to mechanisms and interventions. Alcohol Clin Exp Res. 2013;37:23-30.

66. Suzuki R, Orsini N, Mignone L, Saji S, Wolk A. Alcohol intake and risk of breast cancer defined by estrogen and progesterone receptor status - A meta-analysis of epidemiological studies. Int J Cancer. 2008;122:1832-41.

67. Scoccianti C, Lauby-Secretan B, Bello PY, Chajes V, Romieu I. Female breast cancer and alcohol consumption: A review of the literature. Am J Prev Med. 2014;46 3 Suppl 1:S16-25.

68. Beasley JM, Coronado GD, Livaudais J, Angeles-Llerenas A, Ortega-Olvera C, Romieu I, et al. Alcohol and risk of breast cancer in Mexican women. Cancer Causes Control. 2010;21: 863-70.

69. Schulz M, Hoffmann K, Weikert C, Nöthlings U, Schulze MB, Boeing $\mathrm{H}$. Identification of a dietary pattern characterized by high-fat food choices associated with increased risk of breast cancer: The European prospective investigation into cancer and nutrition (EPIC)-Potsdam study. Br J Nutr. 2008;100:942-6.

70. Brennan SF, Cantwell MM, Cardwell CR, Velentzis LS, Woodside JV. Dietary patterns and breast cancer risk: A systematic review and meta-analysis. Am J Clin Nutr. 2010;91:1294-302.

71. Sánchez-Zamorano LM, Flores-Luna L, Angeles-Llerenas A, Ortega-Olvera C, Lazcano-Ponce E, Romieu I, et al. The Western dietary pattern is associated with increased serum concentrations of free estradiol in postmenopausal women: Implications for breast cancer prevention. Nutr Res. 2016;36:845-54.

72. Neilson HK, Farris MS, Stone CR, Vaska MM, Brenner DR, Friedenreich CM. Moderate-vigorous recreational physical activity and breast cancer risk, stratified by menopause status: A systematic review and meta-analysis. Menopause. 2017;24:322-44.

73. Bernstein L, Henderson BE, Hanisch R, Sullivan-Halley J, Ross RK. Physical exercise and reduced risk of breast cancer in young women. J Natl Cancer Inst. 1994;86:1403-8.

74. Sánchez-Zamorano LM, Flores-Luna L, Angeles-Llerenas A, Romieu I, Lazcano-Ponce E. Healthy lifestyle on the risk of breast cancer. Cancer Epidemiol Biomarkers Prev. 2011;20: 912-22.

75. Renehan AG, Zwahlen M, Egger M. Adiposity and cancer risk: New mechanistic insights from epidemiology. Nat Rev Cancer. 2015;15:484-98.

76. Harvie M, Hooper L, Howell AH. Central obesity and breast cancer risk: A systematic review. Obes Rev. 2003;4:157-73.

77. Amadou A, Ferrari P, Muwonge R, Moskal A, Biessy C, Romieu I, et al. Overweight, obesity and risk of premenopausal breast cancer according to ethnicity: A systematic review and dose-response meta-analysis. Obes Rev. 2013;14:665-78.

78. Harris HR, Willett WC, Terry KL, Michels KB. Body fat distribution and risk of premenopausal breast cancer in the nurses' health study II. J Natl Cancer Inst. 2011;103:273-8.

79. Slattery ML, Sweeney C, Edwards S, Herrick J, Baumgartner K, Wolff $\mathrm{R}$, et al. Body size, weight change, fat distribution and breast cancer risk in Hispanic and non-Hispanic white women. Breast Cancer Res Treat. 2007;102:85-101.

80. John EM, Sangaramoorthy $M$, Hines $L M$, Stern $M C$, Baumgartner KB, Giuliano AR, et al. Overall and abdominal adiposity and premenopausal breast cancer risk among hispanic women: The breast cancer health disparities study. Cancer Epidemiol Biomarkers Prev. 2015;24:138-47.

81. Rosner B, Eliassen AH, Toriola AT, Hankinson SE, Willett WC, Natarajan L, et al. Short-term weight gain and breast cancer risk by hormone receptor classification among pre- and postmenopausal women. Breast Cancer Res Treat. 2015;150:643-53.

82. Wenten M, Gilliland FD, Baumgartner K, Samet JM. Associations of weight, weight change, and body mass with breast cancer risk in Hispanic and non-Hispanic white women. Ann Epidemiol. 2002;12:435-4.

83. Allott EH, Hursting SD. Obesity and cancer: Mechanistic insights from transdisciplinary studies. Endocr Relat Cancer. 2015; 22:R365-86.

84. Collaborative Group on Hormonal Factors in Breast Cancer. Breast cancer and breastfeeding: Collaborative reanalysis of individual data from 47 epidemiological studies in 30 countries, including 50302 women with breast cancer and 96973 women without the disease. Lancet. 2002;360:187-95.

85. Pan H, He Z, Ling L, Ding Q, Chen L, Zha X, et al. Reproductive factors and breast cancer risk among BRCA1 or BRCA2 mutation carriers: Results from ten studies. Cancer Epidemiol. 2014;38:1-8

86. Lakhani SR, Van De Vijver MJ, Jacquemier J, Anderson TJ, Osin PP, McGuffog L, et al. The pathology of familial breast cancer: Predictive value of immunohistochemical markers estrogen receptor, progesterone receptor, HER-2, and p53 in patients with mutations in BRCA1 and BRCA2. J Clin Oncol. 2002; 20:2310-8

87. Scoccianti C, Key TJ, Anderson AS, Armaroli P, Berrino F, Cecchini $M$, et al. European code against cancer $4^{\text {th }}$ edition: Breastfeeding and cancer. Cancer Epidemiol. 2015;39 Suppl 1: S101-6. 